\title{
Integrative metabolomics-flavoromics approach to assess metabolic shifts during ripening of mango (Mangifera indica L.) cultivar Nam Dok Mai Si Thong
}

Ye Lin Aung, Yaowapa Lorjaroenphon, Pinthip Rumpagaporn, Sichaya Sittipod, Wannee Jirapakkul and Kriskamol Na Jom* (1)

\begin{abstract}
Background: Nam Dok Mai Mango (Mangifera indica L.) is considered as one of the famous tropical fruits in Thailand with an attractive taste and fragrance. A rapidly powerful comprehensive technique to investigate the aromatic as well as metabolic compounds is required to follow the ripening stage and identification of biomarkers in mango cv. Nam Dok Mai. To date, only a few omics-based studies have been published on the ripening process of mango. The present study aimed to establish an advanced omics-based approach using integrated metabolomics-flavoromic profiles to follow the ripening process of Nam Dok Mai Si Thong mango fruit.

Results: 56 metabolites and 33 flavor volatile components were detected in Nam Dok Mai Si Thong mango. Palmitic acid shown the highest content in lipid fraction of mango pulp (28\%) followed by linolenic acid (25\%) and linoleic acid (23\%) at various ripening stages during ripening. $\beta$-Sitosterol (3.9\%), campesterol (2.4\%), and sitostanol (2.4\%) were higher at day 0 of ripening. Glycine and leucine were highest at day 4 of ripening (3.4 and 3.0\%, respectively). The highest sucrose level (48.7\%) was observed at 8 days of ripening. Ethyl octanoate (6.2-9.5\%) and ethyl decanoate (5.4-6.5\%) were significantly higher at days 4 to 8 of ripening.

Conclusions: Among 19 biomarkers measured, nine metabolites (palmitic acid, linoleic acid, linolenic acids, $\beta$-sitosterol, sucrose, citric acid, malic acid, glycine, and leucine), and 2 flavors (ethyl octanoate and ethyl decanoate) showed a good correlation with ripening-associated changes at days 0 to 8 during ripening. The biomarkers identified in this study could be used to track the ripening stages of Nam Dok Mai Si Thong mango.
\end{abstract}

Keywords: Nam Dok Mai, Ripening, Metabolomics, Flavoromics, Mangifera indica L.

\footnotetext{
*Correspondence: kriskamol.n@ku.ac.th

Department of Food Science and Technology, Faculty of Agro-Industry,

Kasetsart University, Bangkok 10900, Thailand
} 


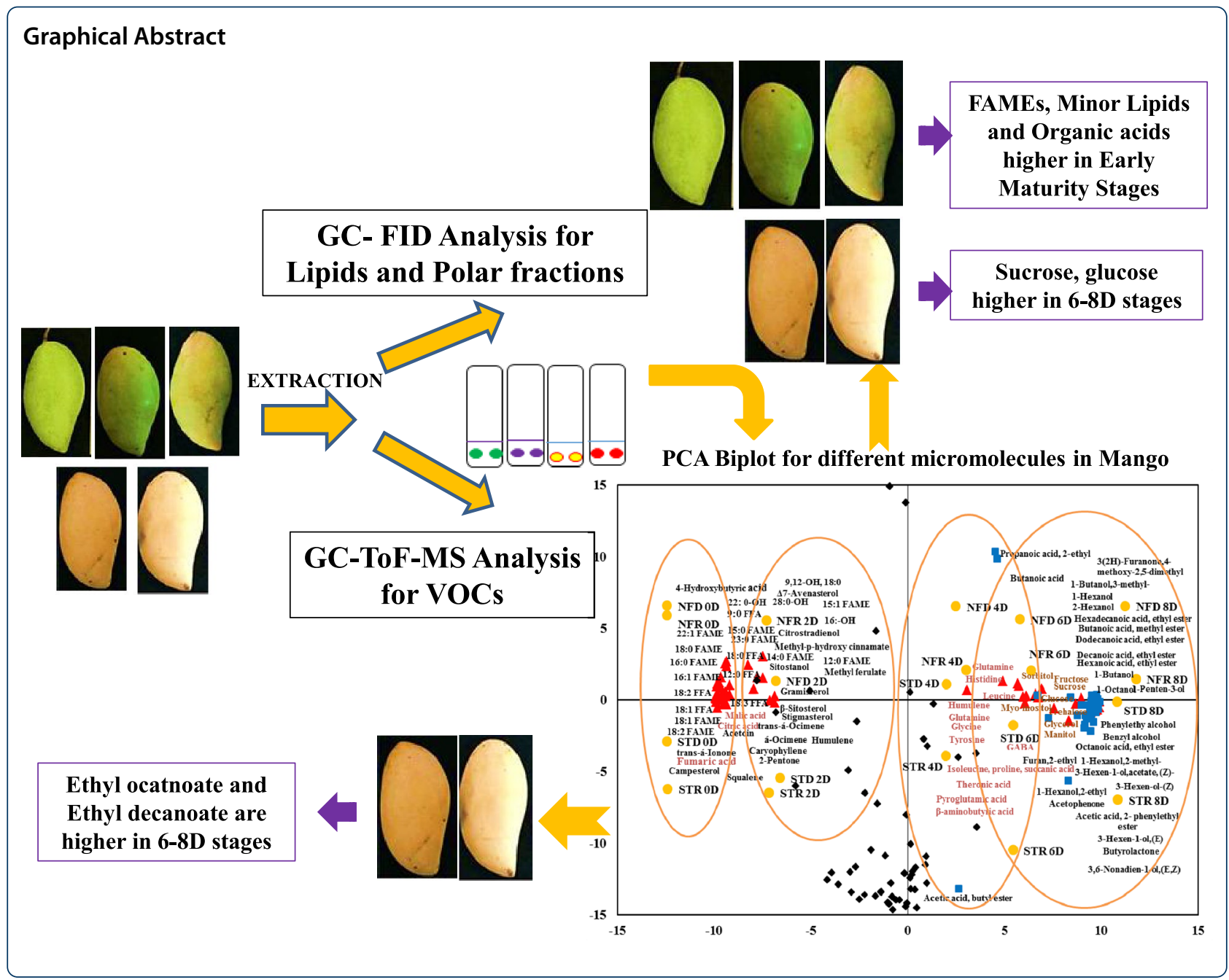

\section{Background}

Mango is the second most worldwide produced tropical climacteric fruit after bananas [1], and is widely grown in Thailand. Because of its distinct texture, flavor, and taste quality, the Thai mango cultivar Nam Dok Mai is well known and widely exported to consumers worldwide [2]. It also contains dietary fiber and antioxidants, such as carotene, that promote consumer health [3]. In climacteric fruit, ripening is dramatically affiliated with textural changes. As previously descried by Prasanna et al. [4], texture changes result from enzymatic degradation of structural and storage polysaccharides usually occurs along with fruit softening. Changes in turgor pressures, cell wall polysaccharides, and starch degradation all contribute to fruit softening.

The pulp ripens at temperatures $>25{ }^{\circ} \mathrm{C}$, but the chlorophyll in the skin is not completely broken down; however, complete chlorophyll destruction can occur even at temperatures at $35^{\circ} \mathrm{C}$. As described by Pino et al. [5], there are $>300$ volatile compounds in different mango cultivars. As the same mentioned as Quijano et al. [6], the volatile compounds responsible for fruit aroma and flavor are produced via metabolic pathways during harvesting, ripening, and postharvest storage.

Mango production in Thailand is all-year-round due to the various micro-climates among various regions. However, the peak season is between April to June. Summer (March-June) is considered to be the best mango season in Thailand with minor timing variation in the northern and the southern region of the country. Since off-season inducing technique is commonly applied, varieties of mangoes are now available all-year-round. Several studies reported for Nam Dok Mai mango cultivars especially for postharvest handling practices related with quality changes during storage at various temperatures [7], reduction of chilling injuries, cold storage in salicylic acid increases enzymatic and non-enzymatic antioxidants on Nam Dok Mai No.4 $[8,9]$, the influence of chitosan 
coating combined with spermidine on anthracnose disease and qualities of Nam Dok Mai mango after harvesting [10]. Furthermore, the previous studies also focus on the physiological behaviors of South East Asian mango cultivars [11], whereas fatty acid composition, physicochemical and thermal properties and crystallization behaviors of mango kernel fat in different Thai mango cultivars have been elucidated. Previous research on the seasonal effects as well as integration of metabolomicsflavoromic approach on Thai mango cultivars still under remained. However, studies on omics technology related to their micromolecules are still needrd.

This research will be applied a new approach for the rapid and reliable fingerprinting of both volatile and non-volatile metabolites by combining metabolomics and flavoromics to follow the ripening stages and detect biomarkers of ripening and shelf-life of mango cultivar Nam Dok Mai Si Thong. Correlations between flavor and metabolite compounds will be identified to provide potential targets for manipulation of ripening mango $\mathrm{cv}$. Nam Dok Mai compositional traits. Furthermore, understanding the related compounds that govern each ripening stage would be useful for the mango growers and exporters as well as mango processing industries, including the production of mango juice, mango wine, and mango beer that have a unique aroma and high level of bioactive compounds.

\section{Results and discussion}

\section{Ripening appearance of Nam Dok Mai Si Thong mango}

Mango samples were analyzed at various stages of ripening during the dry and rainy seasons, from day 0 to day 8 of ripening stages (Fig. 1). The most noticeable changes during ripening were alterations in the external color from green to yellow, which occurred from day 0 to day 8 of ripening. As described by Chin et al. [12], "Chokanan" mango cultivar has changed the color from green to yellow within day 8 of the ripening period at $25 \pm 1{ }^{\circ} \mathrm{C}$. However, Lalel et al. [13] reported that mango ripening occurred within day 9 to day 12 postharvest at an ambient temperature $\left(21 \pm 1{ }^{\circ} \mathrm{C}\right)$. Changes observed in this study during ripening may have been due to the chlorophyll degradation and pigment formation as well as metabolic activities during ripening. On the other hand, there is a broad spectrum of biochemical changes that occur during fruit ripening [4]. A comprehensive understanding of the ripening phenomena will enable us to understand changes to metabolites and flavor compounds that occur during the ripening process. Furthermore, an improved understanding of the fruit ripening process could be used to develop effective storage strategies, reducing postharvest losses and mitigating global food insecurity.

\section{Metabolomic and flavoromic analysis of Nam Dok Mai Si Thong}

Metabolomic analysis resulted in 92 identified and unidentified chromatography peaks in dry and rainy seasons of mango. 56 chromatographic peaks were identified, accounting for $60 \%$ of all metabolites found in mango fruit from day 0 to 8 of ripening. FAMEs $(n=13)$, polar lipids [free fatty acid (FFA), fatty alcohol, and phytosterols; $n=5$ ], sugars (organic sugars and sugar alcohols; $n=8$ ), and acids (organic and amino acids; $n=15$ ) were identified as the four major groups of metabolites. There are $\sim 72 \%$ of all flavor compounds at the different stages of ripening of Nam Dok Mai Si Thong. Among 46 chromatograms, there were 33 identified and 13 unidentified flavor compounds including esters $(n=8)$, alcohols $(n=13)$, ketones and aldehydes $(n=5)$, terpenes $(n=5)$, furans $(n=1)$, and lactones $(n=1)$. Metabolites and flavor compounds during the dry and rainy seasons at different ripening stages were shown in heat map by their

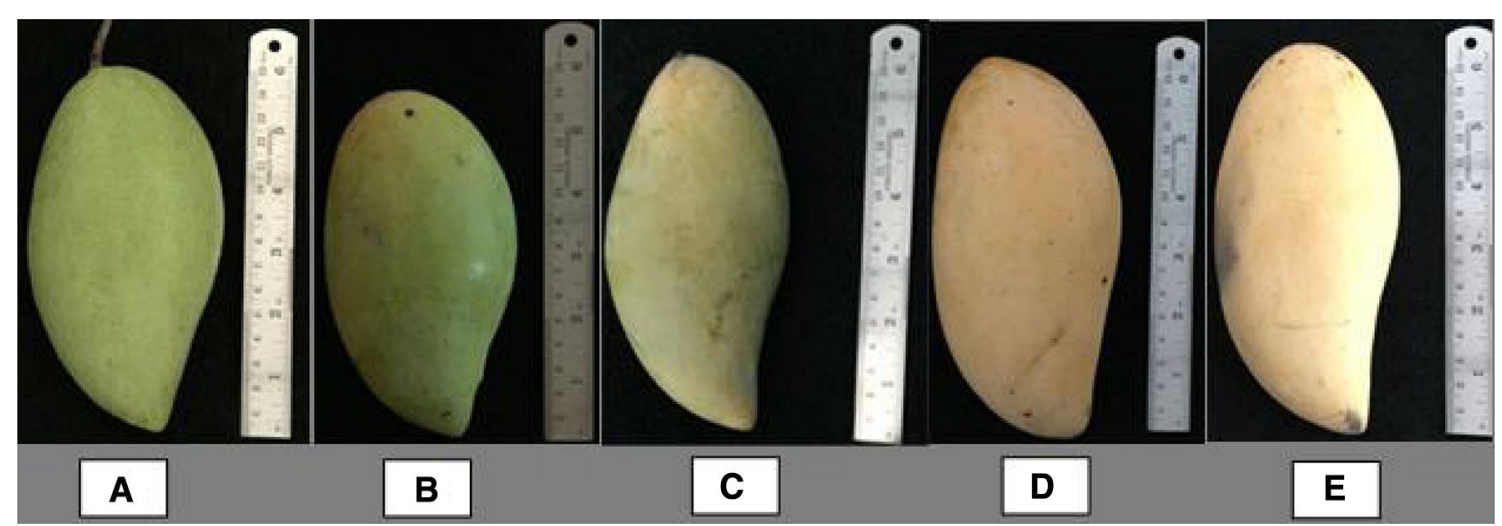

Fig. 1 Different ripening stages of Nam Dok Mai Si Thong mango. Days 0 (A), 2 (B), 4 (C), 6 (D), and 8 (E) of ripening 
relative quantification analysis (Fig. 2). In the present study, the concentrations of several metabolites varied depending on the different ripening stages. The FAME, FFA, fatty alcohols and sterols content were higher in mangoes on day 0 and gradually decreased to day 8 during ripening. The main FAMEs observed in day 0 to 8 mangoes were palmitic acid (16:0) (5.8-5.1\%), palmitoleic acid (16:1 n-7) (2.0-1.1\%), oleic acid (18:1 n-9) (2.5-1.5\%), linoleic acid (18:2 $n-6)(5.3-3.9 \%)$, and linolenic acid (18:3n-3) (5.4-4.8\%). As previous described by Deshpande et al. [14], those fatty acids were also higher in Alphoson and Pari mango pulp. Also, 16:0-OH was the major fatty alcohol and 18:2 $(n-6)$ was the most abundant FFA, ranging from $4.5-1.3$ to $1.3-0.9 \%$, respectively, from day 0 to 8 . The most abundant sterols from day 0 to 8 were $\beta$-sitosterol (3.9-2.0\%), campesterol (2.4$1.0 \%)$, and sitostanol (2.4-1.7\%). Palmitic acid content was the highest at day 0 during both seasons. From 0 to 8 days ripening stages, the total content of palmitic acid was $28 \%$, followed by linolenic acid (25\%), linoleic acid (23\%), oleic acid (10\%), and palmitoleic acid (8\%). Leite Neta et al. [15] studied the pulp and peel of the Brazilian mango "Espada" cultivar and reported that palmitic acid (64.43\%), oleic acid (9.01\%), and palmitoleic acid (8.76\%) were the primary fatty acids found in pulp. Fatty acids are often played as formation of principal flavor volatiles and also primary structural and plant metabolic components and fruit cells. FFAs or fatty acids are released by lipase activity and metabolized by $\beta$-oxidation enzymes and lipoxygenase. Reineccius [16] also reported that the

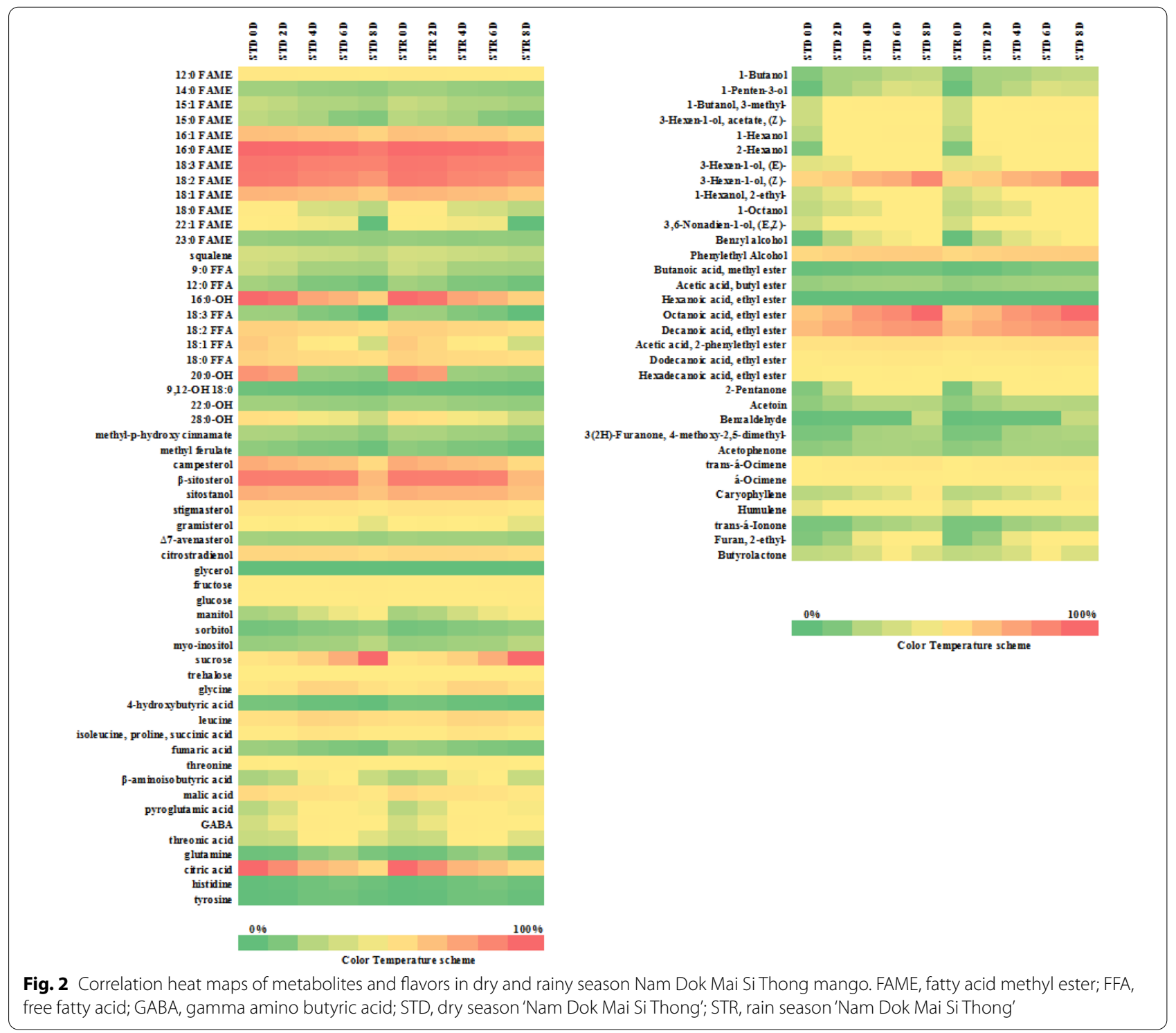


broader range of flavor compounds arisen from lipids was derived from lipoxygenase activity. Vilela et al. [17], also described as the $\beta$-sitosterol was the major component in the pulp of 'Irwin', 'Gomera I', 'Osteen' and 'Rubri Brasil' mango cultivars.

According to Bernardes et al. [18], the critical monosaccharide during the preclimacteric phase is fructose, whereas Dar et al. [19], reported as the sucrose is the predominant sugar in ripe mango. The present study revealed that the sucrose content gradually became higher from day 0 to 8 in both dry and rainy seasons. The sucrose concentration significantly increased at day 8 by $49.7 \%$, which was 18 -fold higher than concentrations at day $0(4.89 \%)$ during ripening. According to Sweetman et al. [20] gluconeogenesis, which results in the generation of glucose from phosphoenolpyruvate, occurred mainly during fruit ripening when sugars accumulate rapidly. Therefore, sucrose accumulation at the beginning of the ripening period (days 0,2 , and 4) could be derived from carbon stored within the mango itself and could be a process of sucrose synthesis that occurs as a result of a major metabolic flux in mango during ripening. Furthermore, increasing sucrose synthase and sucrose phosphate synthase directly controls sugar accumulation in fruit [21]. In the present study, there were 15 amino acids and organic acids were resulted. Citric acid was sixfold higher at day 0 than day 8 by $2.8-17.8 \%$ during ripening. Malic acid was the second most abundant organic acid, with the highest concentration observed in day 0 samples $(2.8 \%)$ and then gradually decreasing until day 8 of the ripening stage. Carbohydrates like glucose are catabolized into pyruvate as a result of glycolysis, which is actively transported into the mitochondria and enters the TCA cycle after being converted to acetyl-CoA. The previous study reported as the condensation of oxaloacetate and acetyl-CoA produces citric acid [22]. Etienne et al. [23] also reported that citrate and malate accumulation was caused by close interactions between metabolism and vacuolar storage. Glycine and leucine concentrations increased from day 0 to 4 samples, ranging from 1.2$3.4 \%$ and $1.9-3.0 \%$, respectively, and decreased at day 8 during ripening. According to Tran et al. [24], succinic acid, fumaric acid, and $\alpha$-ketoglutaric acid levels, which are TCA cycle intermediates, consistently decreased during the day as ripening proceeded.

Total alcohol concentration showed as $33.6 \%$ among the flavor volatiles (Fig. 2). The formation of alcohols could be due to acyl-CoA activity via acyl-CoA reductase and alcohol dehydrogenase [25]. The level of total alcohols in day 8 samples was threefold higher than day 0 samples. Levels of alcohols, such as 1-hexanol, phenylethyl alcohol, 2-hexanol, 1-octanol, and 1-pentan-3-ol, increased as the ripening days increased. The most abundant alcohol compound was 3-hexen-1-ol, (Z) (19.9\%) in day 0 to 8 samples, and gradually increased with increasing ripening stages. Previous studied reported that the $\mathrm{C} 6$ compounds, like 3-hexen-1-ol, (Z), are produced through the hydroperoxide lyase and lipoxygenase pathways [26]. The phenylethyl alcohol content is as high as $10.1 \%$ in the scent of roses. High levels of alcohols could be an essential type of volatile aroma substance in alcoholic beverages. Consequently, these volatile alcohols could be useful for fermentation in the mango wine-making process [27]. Although the number of ester groups was lower among total volatile flavor compounds, the total concentration of esters was $62.0 \%$, which was $\sim$ twofold higher than the concentration of total alcohol compounds in Nam Dok Mai Si Thong at various stages of ripening. Octanoic acid, ethyl ester (2.6-9.5\%), and decanoic acid, ethyl ester (3.5-6.5\%) were the most abundant fatty acid ethyl esters. One of the aromatic compounds primarily responsible for the aroma of juices and wines, octanoic acid, ethyl ester, was highest at day 8 samples in dry and rainy season samples [28]. The major terpenes observed at day 0 to 8 stages were á-ocimene $(0.09-0.5 \%)$, transá-ocimene (0.08-0.2\%), caryophyllene (0.02-0.3\%), and humulene $(0.03-0.08 \%)$. Our findings revealed that monoterpenes and sesquiterpenes gradually increased, peaking at day 6 and 8 of ripening. Humulene is designated by a woody aroma [29] and is also one of the important volatile compounds in mango beer [27]. Nam Dok Mai cultivar contains $\beta$-caryophyllene as a main volatile, exhibiting a distinct volatile composition [30].

There are 12 biomarkers for metabolites (palmitic acid, linoleic acid, linolenic acid, oleic acid, $\beta$-sitosterol, campesterol, sitosterol, sucrose, citric acid, malic acid, glycine, and leucine) and 7 biomarkers for flavors [3-hexen-1-ol (Z), ethyl octanoate, ethyl decanoate, á-ocimene, transá-ocimene, caryophyllene, and humulene] that can efficiently identify through different ripening stages. Among the 12 biomarkers, 9 metabolites (palmitic acid, linoleic acid, linolenic acids, $\beta$-sitosterol, sucrose, citric acid, malic acid, glycine, and leucine) and 2 flavors (ethyl octanoate and ethyl decanoate) displayed noticeable relation with ripening-related changes in day 0 to 8 samples during ripening. Palmitic, linolenic, linoleic and oleic acid were characterized at unripe stage. It indicated that fatty acid degradation or oxidation of unsaturated fatty acid was high in the ripening process of the samples. $\beta$-Sitosterol, campesterol and sitostanol showed the higher content at $0-4 \mathrm{D}$ samples. This might reveal that the enzymatic activity of sterol biosynthesis was stopped at later ripening stage, and the rate of conversion of sterols to derivatives by dehydration, hydrogenation 
and dehydrogenation reactions, increased, while the higher content of sucrose in the fully ripe samples might implied the role of sucrose phosphate synthase. Citric and malic acid content showed higher content at $2 \mathrm{D}$ stages, which might be due to the continued activity of malate dehydrogenase and citrate synthase by TCA cycle. Ethyl octanoate and ethyl decanoate resulted as high content in the fully ripe mango due to the role of ethyleneinducing ester volatile production in climacteric fruits, in particular in controlling alcohol acyltransferases (AAT). The biomarkers identified in this study have the potential to follow the ripening phenomena as well as identify the quality of Nam Dok Mai Si Thong.

PCA was performed using annotated metabolites and flavor compounds to visualize the differences in metabolites and flavor compounds at day 0 to 8 of ripening in Nam Dok Mai Si Thong. PCA is a multivariate data analysis that can show the variance of samples using metabolites as the descriptive data [31]. Figure 3 shows the PCA biplots for Nam Dok Mai Si Thong from dry and rainy seasons at various ripening stages (day 0 to 8). Biplots for metabolites and flavor volatiles are shown separately in Fig. 3A and B. Polar and non-polar compounds were clearly separated along PC2, accounting for $19.56 \%$ of variation, whereas flavor volatiles were prominently grouped together at days 4,6 , and 8 of ripening. The metabolites and flavor compounds shifting along the $\mathrm{PC} 1$ and $\mathrm{PC} 2$. Figure $3 \mathrm{C}$ shows 4 distinct clusters along with the PC. PCA biplot was explained by $75.1 \%$ variance by day 0 to 8 samples during 2 seasons of ripening mango. The day 0 relied on the first cluster group, whereas the second cluster group was occupied with day 2 ripening stages. Day 4 mango fruit relied in the third cluster groups. Most of amino acids accumulated at day 4 of mango fruit ripening. The fourth cluster group was accompanied by day 6 to 8 , which was crucially occupied by esters, alcohols, terpenes, and hydrocarbons, and most volatile flavor compounds were pronounced in this cluster group. Moreover, sugars were significantly pronounced at day 6 to 8 samples of the last cluster group. The most abundant metabolite accumulation was observed at day 0 to 2 samples and included FAMEs, FFAs, fatty alcohols, and sterols. Changes of micromolecules in Nam Dok Mai Si Thong showed minor variation between the dry and rainy seasons, but each constituent showed change with their ripening stages from day 0 to 8 . Therefore, evidence for environmental effects on mango quality and the directionality of changes in quality parameters still need to be identified and further studies are required to examine the ripening process of mango using a metabolomics-flavoromics approach.

Agglomerative hierarchical clustering analysis (AHC) was performed to diagnose and characterize the correlation among the stages of ripening of mango fruit (Fig. 4). PCA and AHC analyses are frequently used in the food and chemistry field [32]. AHC analysis revealed that in both the dry and rainy seasons, day 4 samples were closer to day 6 and 8 samples, while day 2 samples were closer to day 0 mango samples during ripening. This relationship may reflect the metabolomics-flavoromics constituents that shifted between ripening mango (day 0 to 8) during the ripening process.

In Fig. 5, pairwise Spearman's rank correlation analysis presented the correlations between metabolites and flavors during different ripening stages of dry and rainy seasons Nam Dok Mai mango. Among the four fractions of metabolites (FAMEs, FFA and fatty alcohols, sugars acids), FAMEs (e.g., 16:0, 16:1 n-7, 18:0, 18:1 n-9, 18:2 $n-6,18: 3 n-3$, and 20:0) were strongly and positively correlated with sugars, sterols, amino acids, and organic acids. However, FAMEs and polar lipids were strongly and negatively correlated with flavors such as esters, alcohols, aldehydes, ketones, and terpenes. This could be as a result of lipase activity liberates fatty acids and polar lipids that are metabolized by lipoxygenase to make the volatile esters, alcohols, and aldehydes throughout fruit ripening [33]. Deshpande et al. [34] reported that fatty acid concentrations in mango fruit increased during ripening and stabilized finally at around $1 \%$. On the other hand, esters and alcohols were strongly positively correlated with sugars compounds but strongly negatively correlated with citric acid and malic acid. As a result, mango cultivar Nam Dok Mai Si Thong metabolites and volatile flavor components varied in quantity and kind at different stages of ripening.

\section{Conclusions}

Variations in metabolite accumulations may reflect metabolic activity as well as different stages of ripening. Further correlation analysis highlighted a dense degree of metabolic connectivity, revealing the integration and association between metabolites and flavor compounds. To identify the flavors, important bioactive compounds, and ripening phenomena of Nam Dok Mai Si Thong, the technique in the present study would be implied to address the quality of Thai mangoes cultivars in the future. Nam Dok Mai mango could be used as rich source of fatty acids at the day 0 stage, whereas sugar levels are prominent at the day 6 to 8 stages. Sterols and organic acids were rich at the day 0 stage and amino acids were rich at the day 4 stage. Volatile esters and terpenes hydrocarbons were predominant at day 6 to 8 stages, whereas nine metabolites and two flavors showed notable correlation with the identical for ripening changes at day 0 to 8 during mango ripening. The biomarkers could be applied for the observation of ripening phenomena and 

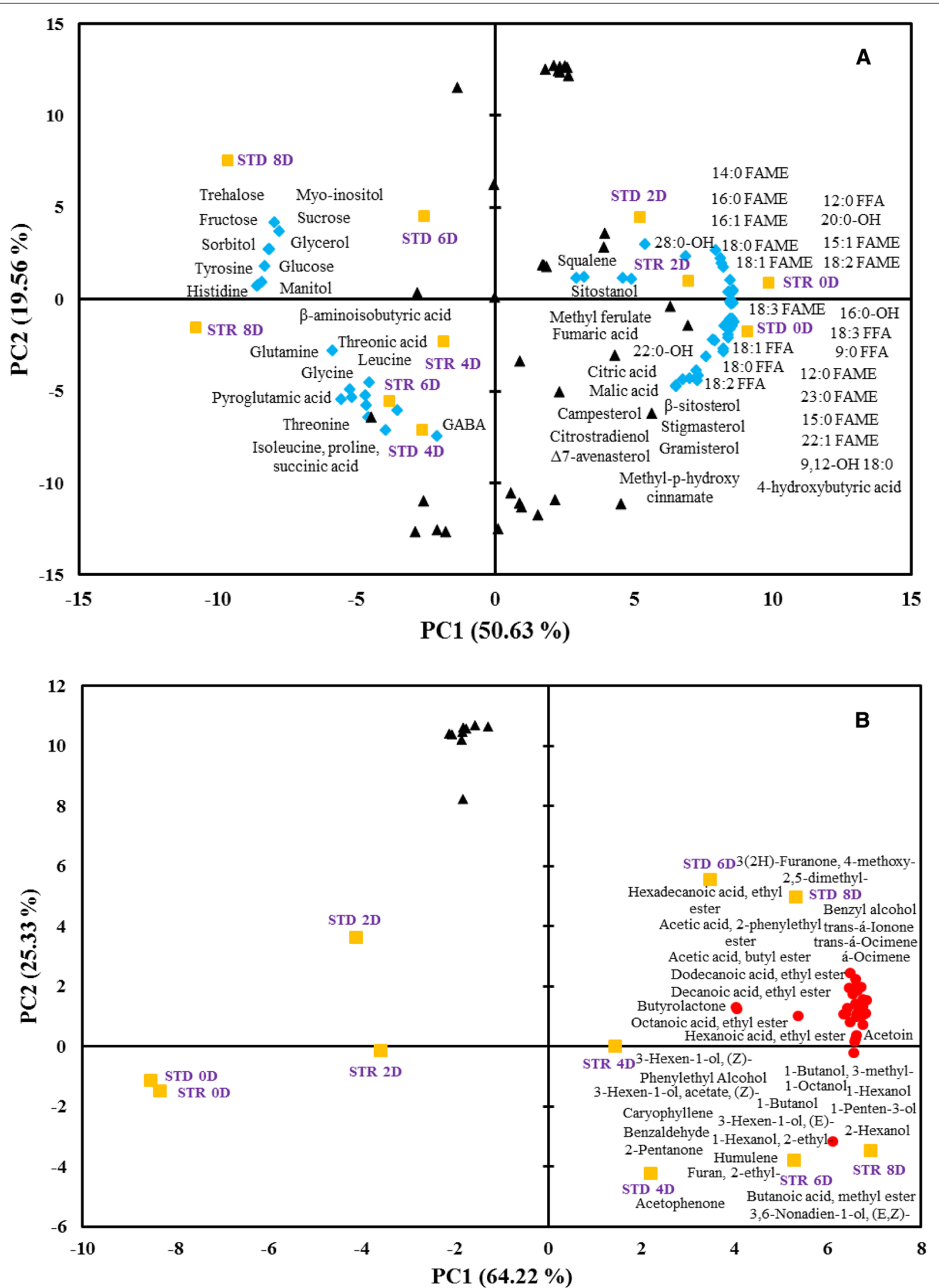

Fig. 3 Biplots of PCA from metabolites (A), flavors (B), and all metabolites and flavors (C) in dry and rainy seasons Nam Dok Mai Si Thong. 0 D, day 0 of ripening, 2 D, day 2 of ripening; 4 D, day 4 of ripening; 6 D, day 6 of ripening; 8 D, day 8 of ripening; FAME, fatty acid methyl ester; FFA, free fatty acid; GABA, gamma amino butyric acid; STD, Nam Dok Mai Si Thong dry season; STR, Nam Dok Mai Si Thong rainy season. Metabolites (blue diamond): flavor compounds (red circle): unknown compounds (black triangle): days at ripening (yellow square) 


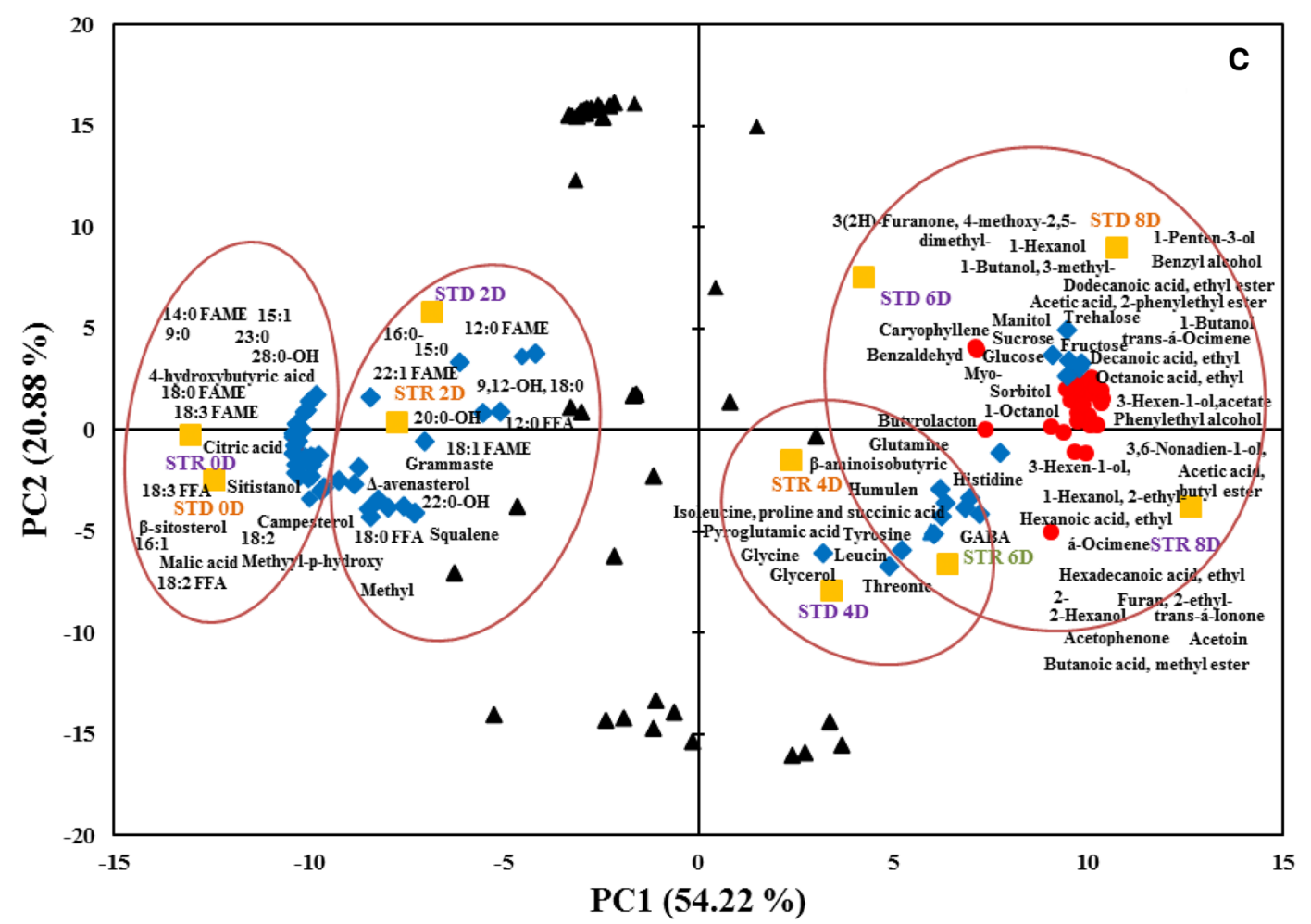

Fig. 3 continued

the nutritive virtue of Nam Dok Mai Si Thong. An integrated metabolomics-flavoromics approach provided a useful alternative tool to follow the dynamic changes of metabolites and flavor compounds at different ripening stages during the dry and rainy seasons.

\section{Material and methods \\ Chemicals}

The chemicals and reagents with analytical grades used in this study were obtained from Fisher Scientific (Thermo Fisher Scientific, Waltham, MA, USA). All standard reagent grade chemicals were from Sigma (Sigma-Aldrich, St. Louis, MO, USA) unless stated otherwise.

\section{Fruit selection and ripening conditions}

Mango samples were obtained from a commercial orchard in Saraburi, Thailand, and were collected 90-100 days after fruit set in May 2016 and instantly transferred to our laboratory at Kasetsart University, Bangkok, Thailand. The dry season samples were taken in mid-March and rainy season samples were collected at the end of June. Mango fruit with weights of 400-420 g were selected according to their homogeneity, with a length of $14-16 \mathrm{~cm}$ and width of 7-9 cm. Ripening indexes were checked as previously described by Sriwimon et al. [35]. To allow ripening, selected samples were placed in a controlled temperature storage chamber at $30 \pm 2{ }^{\circ} \mathrm{C}$ and $75 \pm 2 \%$ relative humidity. Samples were taken on days $0,2,4,6$, and 8 of ripening.

\section{Sample preparation}

After collecting samples based on ripening days, samples were washed, peeled, and cut into $1 \mathrm{~cm}$ cubes, and the fresh mango pulps were analyzed for flavor and freezedried for metabolite analysis (Gamma 2-16 LSC freezedrying machine, Martin Christ, Osterode am Harz, Germany). Freeze-dried mango samples were ground to make powder by using an RS 300 rotor mill (Retsch, Haan, Germany) and stored at $-20^{\circ} \mathrm{C}$ till analyzed.

\section{Metabolomics}

\section{Sample extraction and phase separation}

With some modifications, the solid-phase extraction method is used [36]. The process covered a large range of low molecular components (e.g., sugars, sugar alcohols, acids, amino acids and amines), lipophilic and hydrographic (sugars), fatty acids, methyl esters and sterols). Metabolite compounds have been elicited successively out of $100 \mathrm{mg}$ mango flour puree, which has been 


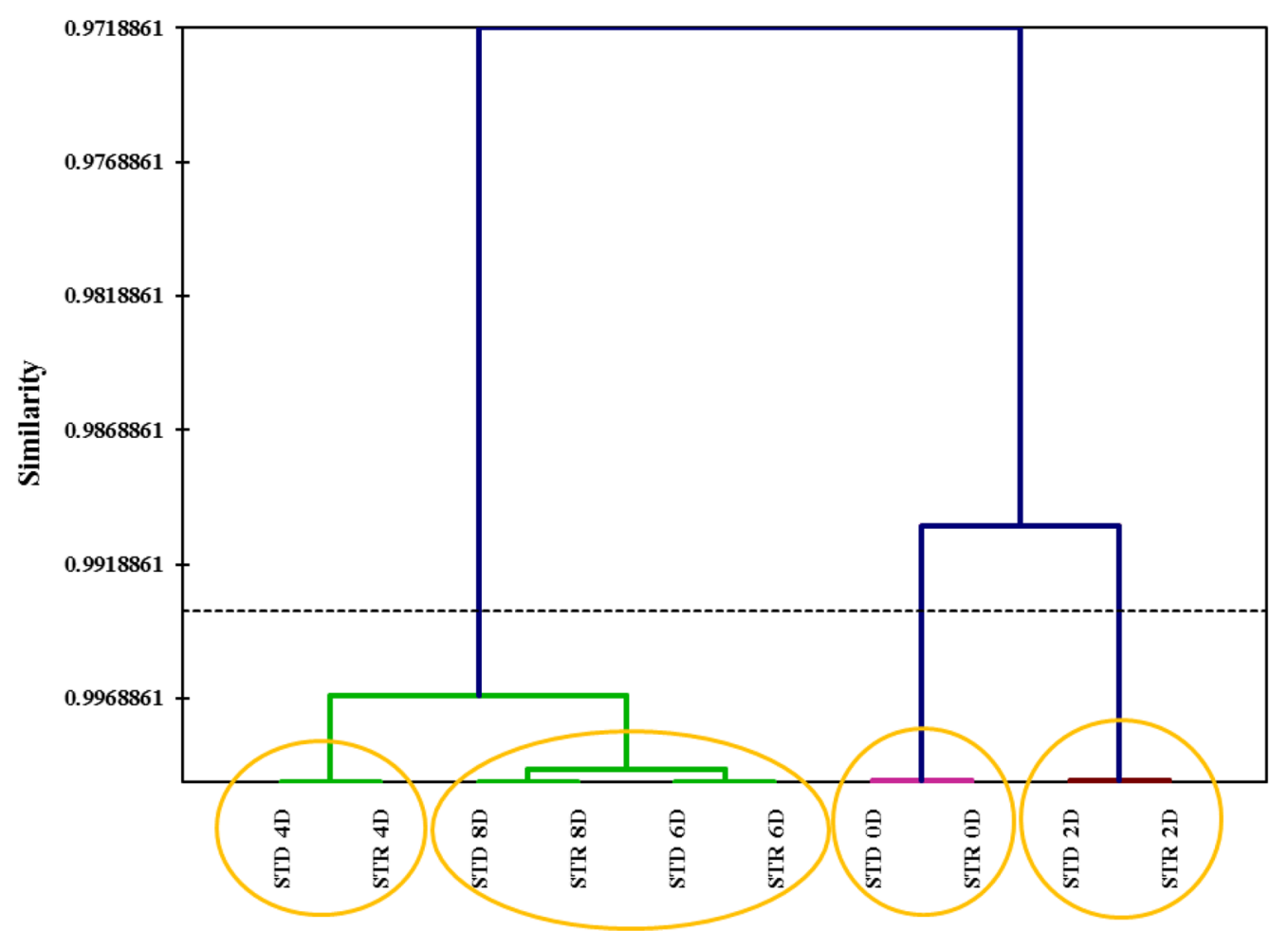

Fig. 4 Agglomerative hierarchical clustering analysis during different ripening stages of dry and rainy seasons Nam Dok Mai Si Thong mango $\left({ }^{*} P \leq 0.05\right)$. 0 D, day 0 of ripening, $2 D$, day 2 of ripening; $4 D$, day 4 of ripening; $6 D$, day 6 of ripening; $8 D$, day 8 of ripening; STD, Nam Dok Mai Si Thong dry season; STR, Nam Dok Mai Si Thong rainy season

weighed into a 3-mL disposal cartridge and then connected to vacuum manifold apparatus. After each cartridge pumped a $200 \mu \mathrm{L}$ solution with methanol, $4 \mathrm{~mL}$ dichloromethane was added to elute the sample lipid part. The polar fraction was elucidated by using $10 \mathrm{~mL}$ of mixed solvents $(80+20 \mathrm{v} / \mathrm{v}$ of methanol and deionized water). For further extraction, all the lipid and polar fractions were dried up till dryness.

\section{Lipid fractionation}

The dried lipid fraction was re-dissolved in a combination of $500 \mu \mathrm{L}$ methyl tert-butyl ether, $300 \mu \mathrm{L}$ methanol, and $50 \mu \mathrm{L}$ sodium methylate for transesterification. Then, $1 \mathrm{~mL}$ dichloromethane and $2 \mathrm{~mL} 0.35 \mathrm{M}$ hydrochloric acid solution were used to achieve selective hydrolysis. The $2 \mathrm{~mL}$ of $0.35 \mathrm{M}$ hydrochloric acid solution was used to separate the upper phase. The lower phase, which included transmethylated lipids, was collected and dried by evaporation. With $250 \mu \mathrm{L}$ of dichloromethane, the lipid residue was re-dissolved. Elution with varied ratios of hexane:methyl tert-butyl ether solution was used to fractionate transmethylated lipids, FAME, and polar lipids. Using a solid-phase microextraction C18-LP cartridge (Vertical Chromatography Co. Ltd.; Nonthaburi, Thailand), the ratio for fatty acid methyl esters was 100:2 v/v and 70:20 v/v for polar lipids. A parallel evaporator was used to evaporate all of the eluents at $50{ }^{\circ} \mathrm{C}$. The fatty acid methyl ester (FAME) residue from the dried fraction was re-dissolved in $300 \mu \mathrm{L}$ of hexane and kept in a glass amber vial. At $70{ }^{\circ} \mathrm{C}$ for $15 \mathrm{~min}$, the dried fraction polar lipids were silylated with $250 \mu \mathrm{L}$ pyridine and $50 \mu \mathrm{L} \mathrm{N}$-trimethylsilyl- $N$-methyl trifluoroacetamide. Lipid fractions were stored at $-20{ }^{\circ} \mathrm{C}$ until using gas chromatography-flame ionized detection (GC-FID) analysis.

\section{Polar fractionation}

The $500 \mu \mathrm{L}$ of polar extracts were evaporated till dry for the sugar fractionation. With $300 \mu \mathrm{L}$ of pyridine and $100 \mu \mathrm{L}$ of trimethylsilylimidazole, the polar residue was silylated. Silylation was carried out for $15 \mathrm{~min}$ in a water bath at $70{ }^{\circ} \mathrm{C}$. Then, for the layer separation process, $300 \mu \mathrm{L}$ of hexane and $300 \mu \mathrm{L}$ of deionized water were added to separate the silylated sugars and sugar alcohol from the sample. The solution was then diluted with $300 \mu \mathrm{L}$ of hexane, and the acid compounds were 


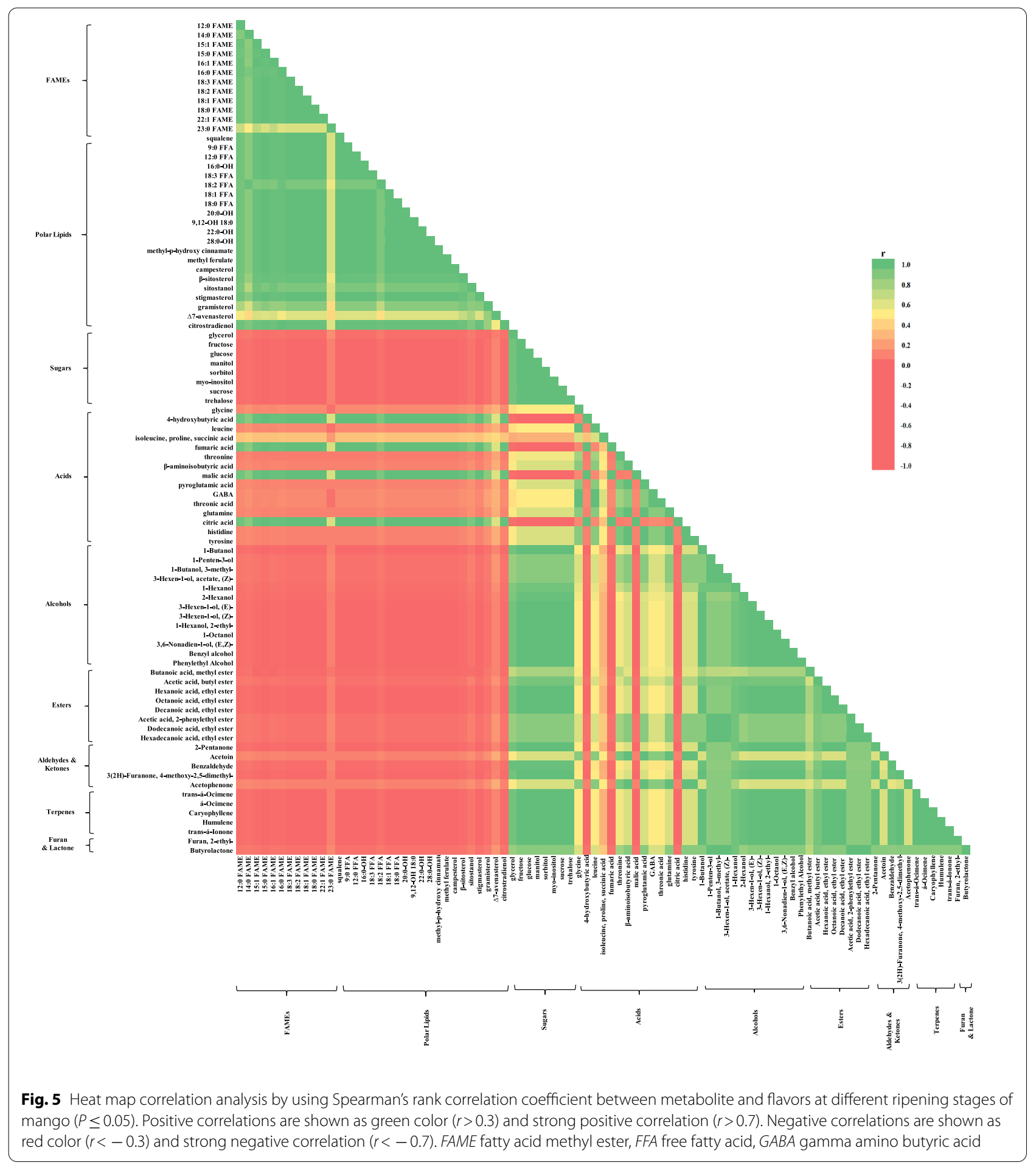

selectively hydrolyzed with $300 \mu \mathrm{L}$ of deionized water. The GC-FID analysis was performed on the top layer of hexane, which contains silylated sugar compounds. The $1 \mathrm{~mL}$ of acid fractions was evaporated until dry with a parallel evaporator, then oximated with $300 \mu \mathrm{L}$ of hydroxyl ammonium chloride in pyridine $(2 \mathrm{mg} /$ $\mathrm{mL}$ ). After $30 \mathrm{~min}$ of oximation at $70{ }^{\circ} \mathrm{C}$, silylation was done by using $100 \mu \mathrm{L}$ of $N$-methyl- $N$-(trimethylsilyl) fluoroacetamide to the reaction at $70{ }^{\circ} \mathrm{C}$ for $15 \mathrm{~min}$. The $500 \mu \mathrm{L}$ of hexane and $300 \mu \mathrm{L}$ of deionized water were 
used for selective hydrolysis. The silylated sugars in the upper phase were eliminated. By adding $150 \mu \mathrm{L}$ of acetonitrile and $100 \mu \mathrm{L}$ of MSTFA at $70{ }^{\circ} \mathrm{C}$ for $60 \mathrm{~min}$, the bottom phase which contained acid compounds was redissolved and silylated. For GC-FID analysis, the sample was immediately stored at $-20{ }^{\circ} \mathrm{C}$.

\section{GC-FID analysis}

GC was carried out according to $\mathrm{Na}$ Jom et al. [36] with partly alteration, applying a $6890 \mathrm{~N}$ GC fitted with a flame ionization detector and a $6890 \mathrm{GC}$ supplied with a HP5973 mass selective detector (Agilent Technologies, Palo Alto, CA, USA).

\section{Flavoromic analysis \\ Sample extraction}

Flavoromic analysis was committed using the method defined by Charve et al. [37]. A solid-phase microextraction (SPME) fiber $(75-\mu \mathrm{m}$ carboxen/polydimethylsiloxane) was used to take out volatiles from the headspace of mango puree solution. The fiber was subjected to the headspace of samples for $10 \mathrm{~min}$ at room temperature. SPME extraction was performed using an incubation temperature of $50{ }^{\circ} \mathrm{C}$ with an extraction period of $20 \mathrm{~min}$ and addition of $0.3 \mathrm{~g} / \mathrm{mL} \mathrm{NaCl}$ to the samples. Sample incubation was done at $50{ }^{\circ} \mathrm{C}$ for 5 min using constant magnetic stirring $(60 \times g)$ prior to SPME extraction. Fiber desorption was done into the injection port of a gas chromatograph at $260{ }^{\circ} \mathrm{C}$ for $10 \mathrm{~min}$. An inlet liner $(78.5 \mathrm{~mm} \times$ OD $6.5 \mathrm{~mm} \times$ ID $0.75 \mathrm{~mm}$ ) was used.

\section{Gas chromatography coupled to time-of-flight mass spectrometry (GC-ToF-MS) analysis}

A 6890 N GC supplied with an HP-5MS capillary column (30 m length, $0.25 \mathrm{~mm}$ id, $0.25 \mathrm{~m}$ film thickness, J\&W Scientific, Folsom, CA, USA) coupled to a ToF-MS analyzer was used for the GC-ToF-MS analysis (Leco Corp., St. Joseph, MI, USA). The following were the operating conditions: ToF-MS, 40-280 u, centroid mode, scan time: $0.1 \mathrm{~s}$, inter-scan time: $0.02 \mathrm{~s}, 2,750 \mathrm{~V}, 70 \mathrm{eV}$; and GC, split $5: 1$; initial oven temperature, $40^{\circ} \mathrm{C}$ increased at $5{ }^{\circ} \mathrm{C} / \mathrm{min}$ to $150{ }^{\circ} \mathrm{C}$ then $40{ }^{\circ} \mathrm{C} / \mathrm{min}$ to $250{ }^{\circ} \mathrm{C}$. For reference compounds and mass spectra libraries, GC chromatograms were compared and discovered using retention times and mass spectra with the NIST mass spectral database version 2.0 (National Institute of Standards) and Technology, Gaithersburg, MD, USA).

\section{Statistical data analysis}

Chromatographic areas of each metabolite were obtained and assimilated using the HP-ChemStation A.06.03 program (Hewlett Packard, Palo Alto, CA). The
ChromaTOF-GC Software v4.50.8.0 (Leco, St.Joseph, MI, USA) was used to process the flavor compounds. Identification was achieved using an analytical standard comparison technique and semi-quantified using a relative investigation with an internal standard area for each fraction. Principal component analysis (PCA), agglomerative hierarchical clustering analysis (AHC) and Spearman's rank collection of all metabolites and flavor compounds with a significance level of $* P \leq 0.05$ using correlation/association tests mode were performed using the XLSTAT-base version 2020.5 (Addinsoft, NY, USA).

\section{Acknowledgements \\ Kasetsart University Research and Development Institute by English proof- reading service and support are acknowledged.}

\section{Authors' contributions}

YLA: writing —original draft, investigation, formal analysis, funding acquisition. KNJ: conceptualization, methodology, supervision, writing —-review and editing. YL, PR, SS, WJ: discussion and writing review. All authors read and approved the final manuscript.

\section{Funding}

This research was supported by the Scholarship of Faculty of Agro-Industry and Graduate School of Kasetsart University, and Thailand Research Fund (TRF), Thailand.

\section{Availability of data and materials}

The data that support the findings of this study are accessible on request from the corresponding author. The data are not publicly available due to privacy or ethical restrictions.

\section{Declarations}

Ethics approval and consent to participate Not applicable.

Consent for publication

Not applicable.

\section{Competing interests}

The authors declare no conflict of interests.

Received: 14 November 2021 Accepted: 5 February 2022

Published online: 03 March 2022

References

1. FAO, URL: http//faostat.fao.org/. Food and Agriculture Organization of the United Nations, 2013.

2. Rimkeeree $\mathrm{K}$, Charoenrein S. Effect of cultivar and ripening stage on quality and microstructure of frozen mangoes (Mangifera indica Linn.). Int J Food Prop. 2014;17(5):1093-108.

3. Reddy L, Reddy O. Effect of fermentation conditions on yeast growth and volatile composition of wine produced from mango (Mangifera indica L.) fruit juice. Food Bioprod Process. 2011;89(4):487-91.

4. Prasanna V, Prabha T, Tharanathan R. Fruit ripening phenomena-an overview. J Crit Rev Food Sci. 2007;47(1):1-19.

5. Pino JA, et al. Volatile components from mango (Mangifera indica L.) cultivars. J Agric Food Chem. 2005;53(6):2213-23.

6. Quijano CE, Salamanca G, Pino JA. Aroma volatile constituents of Colombian varieties of mango (Mangifera indica L.). Flavour Frag J. 2007;22(5):401-6 
7. Noiwan D, et al. Kinetics of mango fruits (Mangifera indica cv. 'Nam Dok Mai Si Thong') quality changes during storage at various temperatures. J Agric Sci. 2017;9(6):199-212.

8. Junmatong $C$, et al. Cold storage in salicylic acid increases enzymatic and non-enzymatic antioxidants of Nam Dok Mai No. 4 mango fruit. J Sci Asia. 2015;41(12):12-21.

9. Junmatong C, et al. Reduction of chilling injury of'Nam Dok Mai No. 4 mango fruit by treatments with salicylic acid and methyl jasmonate. J Agric Sci. 2012;4(10):126.

10. Jongsri $P$, et al. Influence of chitosan coating combined with spermidine on anthracnose disease and qualities of 'Nam Dok Mai' mango after harvest. J Sci Hortic. 2017:224:180-7.

11. Lawson T, et al. Characterization of Southeast Asia mangoes (Mangifera indica L.) according to their physicochemical attributes. J Sci Hortic. 2019;243:189-96.

12. Chin CF, et al. Comparative proteomic analysis on fruit ripening processes in two varieties of tropical mango (Mangifera indica). J Protein J. 2019;38(6):704-15.

13. Lalel HJD, et al. Maturity stage at harvest affects fruit ripening, quality and biosynthesis of aroma volatile compounds in 'Kensington Pride' mango. J Hortic Sci Biotechnol. 2003;78(2):225-33.

14. Deshpande $A B$, et al. Data on changes in the fatty acid composition during fruit development and ripening of three mango cultivars (Alphonso, Pairi and Kent) varying in lactone content. J Data Brief. 2016;9:480-91.

15. Leite Neta, M., et al. Fatty acids profile of pulp and peel of mango (Mangifera indica Linn.) cultivar 'Espada' from Brazilian northeast region. In III International Symposium on Medicinal and Nutraceutical Plants and III Conference of National Institute of Science and 1198. 2012.

16. Reineccius G. Flavor chemistry and technology. Boca Raton: CRC Press: 2005.

17. Vilela $C$, et al. The ripe pulp of Mangifera indica $L$.: a rich source of phytosterols and other lipophilic phytochemicals. J Food Res Int. 2013;54(2):1535-40.

18. Bernardes SAP, et al. Starch mobilization and sucrose accumulation in the pulp of Keitt mangoes during postharvest ripening. J Food Biochem. 2008;32(3):384-95.

19. Dar, M.S., et al., Nutrient and flavor content of mango (Mangifera indica L.) cultivars: an appurtenance to the list of staple foods. In: Nutritional composition of fruit cultivars. 2016, Elsevier. p. 445-467.

20. Sweetman C, et al. Regulation of malate metabolism in grape berry and other developing fruits. J Phytochem. 2009;70(11-12):1329-44.

21. Chen J-W, Zhang S-L, Zhang L-C. Sugar transport, metabolism, accumulation and their regulation in fruits. J Plant Physiol Mol Biol. 2004;30(1):1-10.

22. Guo L, et al. Comparative metabolites and citrate-degrading enzymes activities in citrus fruits reveal the role of balance between ACL and CytACO in metabolite conversions. J Plant. 2020:9(3):350.

23. Etienne $\mathrm{A}$, et al. What controls fleshy fruit acidity? A review of malate and citrate accumulation in fruit cells. J Exp Bot. 2013;64(6):1451-69.

24. Tran T, et al. Application of nitric oxide to extend the shelf life of mango fruit. In: II Southeast Asia symposium on quality management in postharvest systems 1088. 2013

25. Echeverria G, et al. Volatile production, quality and aroma-related enzyme activities during maturation of 'Fuji' apples. J Postharvest Biol Technol. 2004;31(3):217-27.

26. Li X, et al. Relationship between key environmental factors and profiling of volatile compounds during cucumber fruit development under protected cultivation. J Food Chem. 2019;290:308-15.

27. Gasiński A, et al. Volatile compounds content, physicochemical parameters, and antioxidant activity of beers with addition of mango fruit (Mangifera Indica). J Mol. 2020;25(13):3033.

28. Zhu J, et al. Comparison of aroma-active compounds and sensory characteristics of durian (Durio zibethinus L.) wines using strains of Saccharomyces cerevisiae with odor activity values and partial least-squares regression. J Agric Food Chem. 2015;63(7):1939-47.

29. Liu C, et al. Volatile constituents of wild citrus Mangshanyegan (Citrus nobilis Lauriro) peel oil. J Agric Food Chem. 2012;60(10):2617-28.

30. Tamura $\mathrm{H}$, et al. Volatile components of the essential oils in the pulp of four yellow mangoes (Mangifera indica L.) in Thailand. J Food Sci Technol Res. 2000;6(1):68-73.
31. Jolliffe IT, Cadima J. Principal component analysis: a review and recent developments. J Philos Trans R Soc A Math Phys Eng Sci. 2016:374(2065):20150202.

32. Wang $X$, et al. Profiling and quantification of phenolic compounds in Camellia seed oils: natural tea polyphenols in vegetable oil. J Food Res Int. 2017;102:184-94.

33. Fellman J, et al. Factors that influence biosynthesis of volatile flavor compounds in apple fruits. J Hortic Sci. 2000;35(6):1026-33.

34. Deshpande $A B$, et al. Transcriptional transitions in Alphonso mango (Mangifera indica L.) during fruit development and ripening explain its distinct aroma and shelf life characteristics. J Sci Rep. 2017;7(1):8711.

35. Sriwimon W, Boonsupthip W. Utilization of partially ripe mangoes for freezing preservation by impregnation of mango juice and sugars. J LWT Food Sci Technol. 2011:44(2):375-83.

36. Na Jom K, Chanput W, Ngampongsai S. Effect of genetic and climatic variability on the metabolic profiles of black gram (Vigna mungo L.) seeds and sprouts. J Sci Food Agric. 2015;95(8):1662-9.

37. Charve J, et al. Evaluation of instrumental methods for the untargeted analysis of chemical stimuli of orange juice flavour. J Flavour Frag. 2011;26(6):429-40.

\section{Publisher's Note}

Springer Nature remains neutral with regard to jurisdictional claims in published maps and institutional affiliations.

\section{Submit your manuscript to a SpringerOpen ${ }^{\circ}$ journal and benefit from:}

- Convenient online submission

- Rigorous peer review

- Open access: articles freely available online

- High visibility within the field

- Retaining the copyright to your article

Submit your next manuscript at $\boldsymbol{\nabla}$ springeropen.com 